\title{
Papers
}

\section{Decision aids for patients facing health treatment or screening decisions: systematic review}

Annette M O'Connor, Alaa Rostom, Valerie Fiset, Jacqueline Tetroe, Vikki Entwistle, Hilary Llewellyn-Thomas, Margaret Holmes-Rovner, Michael Barry, Jean Jones

\begin{abstract}
Objective To conduct a systematic review of randomised trials of patient decision aids in improving decision making and outcomes. Design We included randomised trials of interventions providing structured, detailed, and specific information on treatment or screening options and outcomes to aid decision making. Two reviewers independently screened and extracted data on several evaluation criteria. Results were pooled by using weighted mean differences and relative risks.

Results 17 studies met the inclusion criteria. Compared with the controls, decision aids produced higher knowledge scores (weighted mean difference $=19 / 100,95 \%$ confidence interval 14 to 25); lower decisional conflict scores (weighted mean difference $=-0.3 / 5,-0.4$ to -0.1$)$; more active patient participation in decision making (relative risk $=2.27,95 \%$ confidence interval 1.3 to 4 ); and no differences in anxiety, satisfaction with decisions (weighted mean difference $=0.6 / 100,-3$ to 4 ), or satisfaction with the decision making process $(2 / 100,-3$ to 7$)$. Decision aids had a variable effect on decisions. When complex decision aids were compared with simpler versions, they were better at reducing decisional conflict, improved knowledge marginally, but did not affect satisfaction.

Conclusions Decision aids improve knowledge, reduce decisional conflict, and stimulate patients to be more active in decision making without increasing their anxiety. Decision aids have little effect on satisfaction and a variable effect on decisions. The effects on outcomes of decisions (persistence with choice, quality of life) remain uncertain.
\end{abstract}

\section{Introduction}

Some medical decisions are complex because the evidence on outcomes is uncertain or the options have different risk-benefit profiles that patients value differently. ${ }^{12}$ Practice guidelines for these difficult decisions recommend that patients understand the probable outcomes of options; consider the personal value they place on benefits versus risks; and participate with their practitioners in deciding about treatment. ${ }^{3}$ Decision aids or shared decision making programmes have been developed as adjuncts to counselling from practi- tioners. Their efficacy has been described in general reports and reviews. ${ }^{4-6}$ We conducted a systematic overview of the trials of decision aids to determine whether they improved decision making and outcomes for patients facing treatment or screening decisions.

\section{Methods}

The search strategy is described in detail elsewhere. We searched the following electronic databases: Medline (1966-April 98); Embase (1980-November 98); PsycINFO (1979-March 98); CINAHL (1983February 98); Aidsline (1980-98); CancerLit (1983April 98); and the Cochrane Controlled Trials Register (1998, Issue 4). Additional studies were searched for in our personal files and the contents lists of Health Expectations (1998), Medical Decision Making (January-March 1986-January-March 1998), and Patient Education and Counselling (January 1995-February 1998).

We included randomised controlled trials comparing decision aids to controls or alternative interventions. Participants were 14 years and over deciding about screening or treatment options. Decision aids were defined as interventions designed to help people make specific and deliberative choices among options (including the status quo) by providing (at the minimum) information on the options and outcomes relevant to a patient's health. The aid may also have included information on the disease or condition; probabilities of outcomes tailored to personal health risk factors; an explicit exercise to clarify values; information on others' opinions; and guidance or coaching in the steps of decision making and communicating with others. We excluded studies involving hypothetical choices; decisions regarding lifestyle changes, entry to a clinical trial, or general advance directives; education programmes not geared to a specific decision; and interventions designed to promote compliance or to elicit informed consent for a recommended option.

Evaluation of outcomes depends on the framework used to develop the decision aids. ${ }^{5-13}$ To ascertain whether the decision aids achieved their objectives, we examined a broad range of positive or negative effects on decision making processes and outcomes of decisions. Although the decision aids focused on diverse clinical decisions, many had similar objectives such as improving knowledge, satisfaction, and participation in

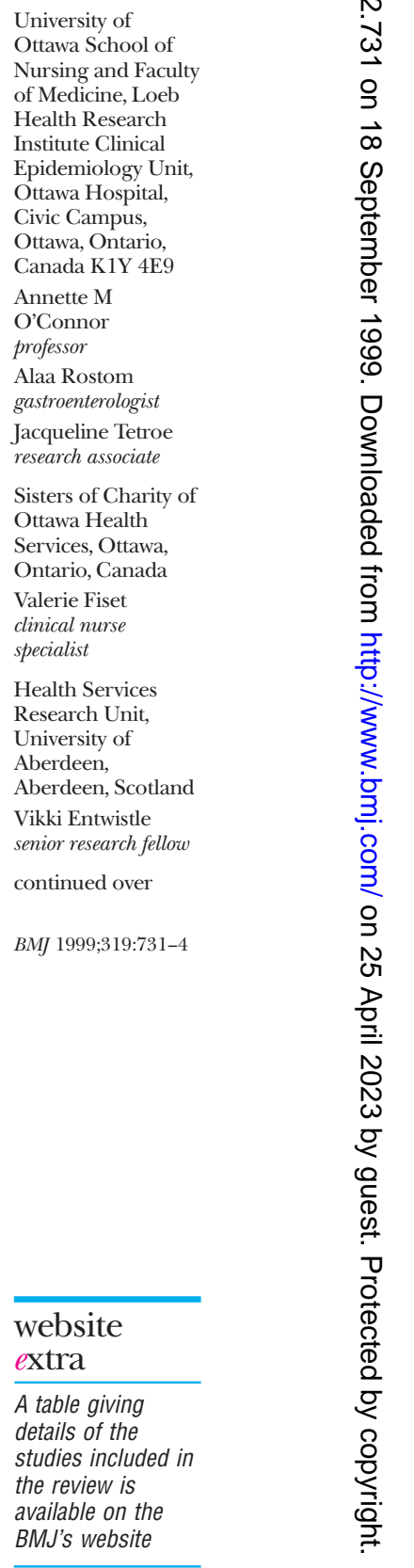

www.bmj.com 
University of Toronto, Institute for Clinical

North York,

Ontario, Canada

Hilary

Llewellyn-Thomas

professor

Department of State University, East Lansing MI, USA

Margaret

Holmes-Rovner

professor

General Medicine Unit, Massachusett General Hospital, Boston, MA, USA

Michael Barry

chief, general medicine

unit

Dundas, Ontario,

Canada

Jean Jones

consumer health

advocate

Correspondence to:

A O'Connor

aoconnor@LRI.CA
Evaluative Sciences, Medicine, Michigan

decision making and reducing decisional conflict. Other outcomes included the choices patients selected, anxiety, and health related quality of life.

Two reviewers (VF, AR, or JT) screened each study and extracted data independently using standardised forms. Inconsistencies were resolved by discussion and consensus. Missing data were obtained from the authors when possible.

The results of the studies were described individually and pooled when similar measures were used. We used RevMan V3.1 ${ }^{14}$ to estimate a weighted treatment effect (with 95\% confidence intervals). We used weighted mean differences for continuous measures and Mantel-Haenszel methods to calculate pooled relative risks for dichotomous outcomes. Heterogeneity was tested with a $\chi^{2}$ test $(\alpha=0.10)$. If clinically and statistically appropriate, heterogeneous data were analysed with a random effects model.

\section{Results}

We identified 10387 unique citations from the electronic databases and nine studies from personal files and contacts. Of these, 500 citations focused on patient decision making and 17 met our inclusion criteria. ${ }^{15-31}$

Table 1 Effect of decision aids on patient's knowledge of options and outcomes

\begin{tabular}{|c|c|c|c|c|c|c|}
\hline \multirow[b]{2}{*}{ Decision } & \multicolumn{2}{|c|}{ Decision aid } & \multicolumn{2}{|c|}{ Comparison group } & \multirow[b]{2}{*}{ Weight } & \multirow[b]{2}{*}{$\begin{array}{c}\text { Mean } \\
\text { difference } \\
(95 \% \mathrm{Cl})\end{array}$} \\
\hline & $\begin{array}{c}\text { No of } \\
\text { patients }\end{array}$ & $\begin{array}{c}\text { Mean (SD) } \\
\text { knowledge } \\
\text { score }\end{array}$ & $\begin{array}{l}\text { No of } \\
\text { patients }\end{array}$ & $\begin{array}{c}\text { Mean (SD) } \\
\text { knowledge } \\
\text { score }\end{array}$ & & \\
\hline \multicolumn{7}{|l|}{ Compared with usual care } \\
\hline Benign prostate disease $\mathrm{s}^{15}$ & 104 & $75(45)$ & 123 & $54(45)$ & 14.1 & 21 (9 to 33) \\
\hline Ischaemic heart disease ${ }^{25}$ & 86 & $75(17)$ & 94 & $62(17)$ & 29.4 & 13 (8 to 18 ) \\
\hline Ischaemic heart disease ${ }^{16}$ & 61 & $83(16)$ & 48 & $58(16)$ & 26.4 & 25 (19 to 31$)$ \\
\hline BRCA1 gene test ${ }^{22}$ & 122 & $69(19)$ & 164 & 49 (21.7) & 30.1 & 20 (15 to 25$)$ \\
\hline Total (random effects $\chi^{2}=9.6$ & 373 & & 429 & & 100 & 19 (14 to 25$)$ \\
\hline
\end{tabular}

(df =3), Z=6.85)

Compared with less intensive decision aid

\begin{tabular}{lcccccc}
\hline Hormone therapy $^{28}$ & 83 & $87(11)$ & 87 & $84(12)$ & 47.4 & $3(-0.4$ to 6) \\
\hline Hormone therapy $^{26}$ & 81 & $75(20)$ & 84 & $71(21)$ & 14.3 & 4 (-2 to 10) \\
\hline Prenatal screen $^{24}$ & 67 & $88(15)$ & 88 & $87(16)$ & 24.7 & $0.9(-4$ to 6) \\
\hline Mastectomy $^{29}$ & 30 & $83(12)$ & 30 & $76(14)$ & 13.5 & $6(-0.3$ to 13) \\
\hline $\begin{array}{l}\text { Total (fixed effects } \chi^{2}=1.8 \\
\text { (df }=3), Z=254)\end{array}$ & 261 & & 289 & & 100 & $3(0.7$ to 5)
\end{tabular}
(df $=3), Z=2.54$

Knowledge tests regarding options and outcomes were specific to the decision and were scored from 0 ( $0 \%$ items correct) to $100(100 \%$ items correct).

Table 2 Effect of decision aids on decisional conflict

\begin{tabular}{|c|c|c|c|c|c|c|}
\hline \multirow[b]{2}{*}{ Decision } & \multicolumn{2}{|c|}{ Decision aid } & \multicolumn{2}{|c|}{ Comparison group } & \multirow[b]{2}{*}{ Weight } & \multirow[b]{2}{*}{$\begin{array}{c}\text { Mean } \\
\text { difference } \\
(95 \% \mathrm{Cl})\end{array}$} \\
\hline & $\begin{array}{l}\text { No of } \\
\text { patients }\end{array}$ & $\begin{array}{c}\text { Mean (SD) } \\
\text { conflict } \\
\text { score }\end{array}$ & $\begin{array}{l}\text { No of } \\
\text { patients }\end{array}$ & $\begin{array}{c}\text { Mean (SD) } \\
\text { conflict } \\
\text { score }\end{array}$ & & \\
\hline \multicolumn{7}{|l|}{ Compared with usual care } \\
\hline $\begin{array}{l}\text { Prostate specific antigen } \\
\text { test }^{19}\end{array}$ & 50 & $1.8(0.5)$ & 50 & $2.2(0.7)$ & 27.5 & $-0.4(-0.7$ to -0.2$)$ \\
\hline $\begin{array}{l}\text { Ischaemic heart } \\
\text { disease } e^{25}\end{array}$ & 86 & $2.1(1.5)$ & 94 & $2.1(1.5)$ & 8.1 & $0.0(-0.4$ to 0.4$)$ \\
\hline
\end{tabular}

Compared with less intensive decision aid

\begin{tabular}{lcccccc}
\hline Hormone therapy $^{28}$ & 83 & $2.6(1.0)$ & 89 & $3.0(1.0)$ & 17.8 & $-0.4(-0.7$ to -0.1$)$ \\
\hline Hormone therapy $^{26}$ & 81 & $2.1(0.6)$ & 84 & $2.3(0.6)$ & 46.6 & $-0.2(-0.4$ to -0.02$)$ \\
\hline $\begin{array}{c}\text { Total (fixed effects } \\
\chi^{2}=3.89(\mathrm{df}=3),\end{array}$ & 300 & & 317 & & 100 & $-0.3(-0.4$ to -0.1$)$ \\
$Z=4.3)$ & & & & & & \\
\hline
\end{tabular}

Decisional conflict ranges theoretically from 1 (strong agreement that one is certain, informed, clear about values, and supported in decision making) and 5 (strong disagreement). Scores above 2.5 are associated with decision delay and those below 2 are associated with decision implementation. A negative mean difference means the decision aid had a positive benefit.
The decision aids focused on 11 screening or treatment decisions (see BMJ's website for details). All aids included information on the clinical problem in addition to information on the options and outcomes. Over half included outcome probabilities, examples of others, and guidance in the steps of decision making. A quarter included a values clarification exercise.

Compared with usual care (table 1), decision aids improved average knowledge scores for the options and outcomes by 13 to 25 points out of 100 (weighted mean difference $=19,95 \%$ confidence interval 14 to 25$)$. Compared with simpler interventions, more intensive decision aids improved average knowledge scores by 0.9 to 6 points (weighted mean difference $3,0.7$ to 5 ).

Decision aids had a positive impact on decisional conflict in three of four studies (table 2) with reductions ranging from 0.2 to 0.4 out of 5 (weighted mean difference $=0.3,0.1$ to 0.4 ). When the subscales of decisional conflict were examined (data not shown), all studies showed that decision aids were better than usual care or simpler aids in improving patients' perceptions of "feeling informed."192526 In two of three studies, decisions aids also made patients feel clear about personal values and supported in decision making. ${ }^{19}{ }^{26}$ The uncertainty subscale improved decisional conflict in the short term but not the long term in one study, ${ }^{28}$ and in another the perceived effective decision subscale improved. ${ }^{19}$

Three studies evaluated satisfaction with the decision making process and satisfaction with the decision using similar interventions, designs, and measures. $^{151625}$ One study found that decision aids improved satisfaction with the decision making process, ${ }^{15}$ but the pooled difference was not significant (weighted mean difference $=2,-3$ to 7 ). There were no significant differences between usual care and decision aids in satisfaction with the decision in either the individual trials or in the pooled studies (weighted mean difference $=0.6,-3$ to 4 ). Two other studies that used different measures also found no significant differences in satisfaction with the decision. ${ }^{24} 28$

Fourteen studies assessed the effect of decision aids on the decision made by the participants (table 3 ). In trials examining decisions about major surgery, decision aids reduced the preference for the more intensive treatment by $21-42 \%$ (relative risk $=0.74$, $95 \%$ confidence interval 0.6 to 0.9 ). In contrast, decision aids did not influence preferences for circumcision of newborn babies $(0.96,0.85$ to 1.07$)$.

Decision aids significantly reduced preferences for prostate specific antigen testing (by 21-48\%) in two studies but had no effect in another. There was significant heterogeneity when results were pooled, and the relative risk with a random effects model was not significant $(0.83,0.6$ to 1.3$)$. Preferences for screening for breast cancer genes and prenatal testing were not affected by decision aids in individual or pooled studies $(1.08,0.95$ to 1.22$)$.

Decision aids increased preferences for hepatitis B vaccine by $76 \%$ but did not affect decisions about dental surgery. Decisions regarding hormone therapy were not affected when more intensive methods were compared with simpler methods to aid decisions.

In three studies decision aids showed a consistent trend in increasing the proportion of participants assuming a more active role in decision making 
compared with usual case controls (pooled relative risk $=2.27,1.3$ to 4$).{ }^{18} 1925$

We were unable to combine the results of some studies because of lack of information on standard deviations. One study found that decision aids significantly reduced the decline in quality of life after treatments for benign prostatic hypertrophy, ${ }^{15}$ but a study focusing on treatments for ischaemic heart disease showed no difference. ${ }^{16}$ Four studies showed that the use of decision aids did not affect patients' anxiety. ${ }^{18} 1924{ }^{30}$ One study found that patients receiving a decision aid with detailed outcome descriptions and probabilities had more realistic expectations (accurate perceptions of the probabilities of outcomes) than those who did not have this information included. ${ }^{26}$

\section{Discussion}

Despite the variability in decisions, interventions, and measurement, the trials were consistent in showing that decision aids do a better job than usual care in improving patients' knowledge about options, reducing their decisional conflict, and stimulating patients to take a more active role in decision making without increasing their anxiety. Decision aids had a variable effect on decisions and virtually no effect on satisfaction. The effects on the outcomes of decisions (such as quality of life) are still uncertain. When compared with simpler versions, more intensive decision aids reduced decisional conflict, improved knowledge marginally, and had no different effect on satisfaction.

\section{Knowledge, comfort, and empowerment}

The largest and most consistent benefit of decision aids over usual care is better knowledge of options and outcomes. The 19\% improvement in scores is clinically important because the scores of people in the usual care group were inadequate for informed decision making and they often made different decisions. These results suggest that doctors' usual methods may not be good enough for informing patients about these complex, value laden decisions. Patients need to comprehend the options and outcomes in order to consider and communicate the personal value they place on the benefits versus the harms.

Decision aids help patients feel more comfortable with their choices, as shown by the reduced decisional conflict scores. Patients uniformly feel more informed about options, and in some cases (notably primary care settings) feel clearer regarding personal values and supported in decision making. The improvement is one to two thirds of a standard deviation. Cross sectional studies suggest that this shift places more patients in the zone where they are more likely to follow through their decisions. However, the effect of reduced decisional conflict on persistence with choices needs to be established prospectively.

Decision aids increased active participation in decision making. The relative and absolute size of the effect was much greater in the Davison studies, ${ }^{18}{ }^{19}$ possibly because coaching was part of the interventions.

\section{Altering choices}

The variable effect of decision aids on patients' decisions may be due to several reasons. Firstly, most
Table 3 Effect of decision aids on patients' decisions

\begin{tabular}{|c|c|c|c|c|c|c|}
\hline \multirow[b]{2}{*}{ Decision } & \multicolumn{2}{|c|}{ Decision aid } & \multicolumn{2}{|c|}{$\begin{array}{l}\text { Comparison } \\
\text { intervention }\end{array}$} & \multirow[b]{2}{*}{ Weight } & \multirow[b]{2}{*}{$\begin{array}{l}\text { Relative risk } \\
(95 \% \mathrm{Cl})\end{array}$} \\
\hline & $\begin{array}{l}\text { No of } \\
\text { patients }\end{array}$ & $\begin{array}{c}\% \\
\text { choosing } \\
\text { option }\end{array}$ & $\begin{array}{c}\text { No of } \\
\text { patients }\end{array}$ & $\begin{array}{c}\% \\
\text { choosing } \\
\text { option }\end{array}$ & & \\
\hline \multicolumn{7}{|l|}{ Major surgery } \\
\hline $\begin{array}{l}\text { Coronary } \\
\quad \text { revascularisation }^{16}\end{array}$ & 61 & 41 & 48 & 58 & 26.4 & $0.7(0.5$ to 1.0$)$ \\
\hline $\begin{array}{l}\text { Coronary } \\
\quad \text { revascularisation }^{25}\end{array}$ & 86 & 59 & 94 & 76 & 57.2 & $0.79(0.6$ to 1.0$)$ \\
\hline Prostatectomy ${ }^{15}$ & 104 & 5 & 123 & 8 & 6.2 & 0.74 (0.3 to 2$)$ \\
\hline Mastectomy $^{29}$ & 30 & 24 & 30 & 42 & 10.1 & $0.58(0.3$ to 1.0$)$ \\
\hline $\begin{array}{l}\text { Total (fixed effects } \chi^{2}=0.73 \\
\quad(\mathrm{df}=3), Z=3.18)\end{array}$ & 281 & & 295 & & 100 & $0.74(0.6$ to 0.9$)$ \\
\hline \multicolumn{7}{|l|}{ Circumcision of newborn boys } \\
\hline Maisels et al ${ }^{23}$ & 23 & 91.3 & 28 & 96.4 & 67.3 & 0.95 (0.8 to 1.1$)$ \\
\hline Herrara et $\mathrm{al}^{21}$ & 56 & 84 & 47 & 87 & 32.7 & $1.07(0.9$ to 1.3$)$ \\
\hline $\begin{array}{l}\text { Total }\left(\chi^{2}=0.02(\mathrm{df}=1),\right. \\
Z=0.76)\end{array}$ & 79 & & 75 & & & $0.96(0.85$ to 1.07$)$ \\
\hline \multicolumn{7}{|c|}{ Testing for prostate specific antigen } \\
\hline Davison and Degner $^{19}$ & 50 & 48 & 50 & 38 & 31.1 & $1.26(0.8$ to 2$)$ \\
\hline Flood et $\mathrm{a}^{20}$ & 103 & 11.7 & 93 & 22.6 & 21.8 & $0.52(0.3$ to 1.0$)$ \\
\hline Wolf et al ${ }^{31}$ & 103 & 60.2 & 102 & 76.5 & 47.2 & $0.79(0.6$ to 0.9$)$ \\
\hline $\begin{array}{l}\text { Total (random effects } \\
\left.\quad \chi^{2}=5.56(\mathrm{df}=2), Z=0.91\right)\end{array}$ & 256 & & 245 & & 100 & 0.83 (0.6 to 1.3) \\
\hline \multicolumn{7}{|l|}{ Other screening } \\
\hline BRCA1 gene test ${ }^{22}$ & 122 & 69.7 & 164 & 65.2 & 38 & 1.07 (0.9 to 1.3$)$ \\
\hline Amniocentesis ${ }^{30}$ & 441 & 37 & 431 & 34.1 & 62 & 1.08 (0.9 to 1.3$)$ \\
\hline $\begin{array}{l}\text { Total (fixed effects } \chi^{2}=0.02 \\
\text { (df }=1), Z=1.15)\end{array}$ & 563 & & 595 & & 100 & 1.08 (0.95 to 1.22$)$ \\
\hline \multicolumn{7}{|l|}{ Other } \\
\hline Hepatitis B vaccine ${ }^{17}$ & 753 & 23.4 & 263 & 13.3 & & 1.76 (1.3 to 2.5$)$ \\
\hline Dental surgery ${ }^{27}$ & 37 & 85 & 37 & 70.3 & & 1.19 (0.9 to 1.5) \\
\hline Hormone therapy ${ }^{26 *}$ & 81 & 13.6 & 84 & 15.5 & & $0.88(0.4$ to 1.8$)$ \\
\hline
\end{tabular}

${ }^{*}$ Comparison between more intensive and less intensive decision aids.

studies were underpowered to detect important differences. Secondly, some of the 11 options may have been underused at baseline and others overused. This would influence the direction of effect once patients become informed and involved in decision making. Thirdly, patients may react differently to the outcomes being considered in the different decisions. Some decisions may be driven predominantly by the probabilities of outcomes and others by the values for outcomes. For example, the aids seem to have a small effect on decisions about major surgical procedures. This may be because patients have inflated perceptions of the probability of benefit and do not understand the probabilities of risks and uncertainties in evidence of effectiveness. When given better knowledge of the outcomes and their associated probabilities, fewer patients may decide that the benefits outweigh the risks. In contrast, decision aids had little effect on circumcisions. This decision may be driven more by values and norms than by perceived probabilities of medical outcomes, as is suggested by the high rates of use in both arms of the trials.

\section{Satisfaction}

The studies showed no effect on satisfaction with decision making. This may because it is difficult to show improvements in satisfaction when control ratings are already quite high and when choices are inherently difficult because of competing benefits and risks. Furthermore, once the decision is made, people may find it more psychologically comforting to say that they 


\section{What is already known on this topic}

Patient decision aids or shared decision making programmes aim to help patients come to informed decisions

Studies of their effectiveness have often been small and have focused on a wide range of medical conditions

\section{What this study adds}

Decision aids are better than usual care in improving patients' knowledge, comfort, and participation in decision making without increasing anxiety

They have little effect on satisfaction and variable effect on patients' decisions

Compared with simpler versions, more detailed aids improve patients' comfort with decision making and marginally improve knowledge

are satisfied with it than to entertain doubts about what they chose. ${ }^{32}$

\section{Further research}

The small differences between simpler and more complex versions of decision aids indicate a need to establish the essential ingredients in decision aids and to identify the patients who are most likely to benefit from more complex versions.

There are several gaps in research. Few studies examined the effects on persistence with choices or health outcomes. We also know little about doctors' views about decision aids, the effect on patient-doctor interactions, and cost effectiveness. More trials are needed to gain a better understanding of what types of decision support work with which types of patients. Baseline predisposition toward choices, preference for participation in decision making, age, sex, ethnicity, and education may all have a bearing on the effectiveness of decision aids. Future reviews would be aided if investigators used standard search terms (such as "shared decision making") and gave structured reports of the composition of decision aids and comparison interventions. Moreover, people who develop and use decision aids need to reach a consensus on a minimum set of criteria for evaluating their effects.

Contributors: All authors contributed to the design of the protocol, the interpretation of results, and the revision and final approval of the final paper. AO'C led the team and JT coordinated the project. AO'C, MH-R, AR, VF, and JT pilot tested the data extraction forms. AR, VF, and JT screened studies and extracted data. AR, JT, and AO'C analysed the results. The Cochrane Consumers and Communication Review Group (editor Alex Jadad) provided peer review and advice regarding the research protocol. Maire O'Donnell from the University of Aberdeen Health Services Research Unit assisted with literature searching. AO'C is the study guarantor.

Funding: The overview was supported by a group grant from the Medical Research Council of Canada. At the time of the study AO'C was funded by the Ontario Ministry of Health, VE held a special research fellowship from the Leverhulme Trust, and HL-T was a national health scholar funded by Health Canada's National Health Research Development Program.

Competing interests: None declared.
1 Eddy DM. A manual for assessing health practices and designing practice policies: the explicit approach. Philadelphia: American College of Physicians, 1992.

2 Kassirer JP. Incorporating patients' preferences into medical decisions. $N$ Engl J Med 1994;330:1895-6.

3 American College of Physicians. Guidelines for counselling postmenopausal women about preventive hormone therapy. Ann Intern Med 1992;117:1038-41.

4 O'Connor AM, Drake ER, Fiset VJ, Page J, Curtin D, Llewellyn-Thomas, HA. Annotated bibliography: studies evaluating decision support interventions for patients. Can J Nurs Res 1997;29:113-20.

5 Research Triangle Institute. Consumer health informatics and patient decision-making. Rockville, Maryland: Agency for Health Care Policy and Research, 1997. (AHCPR publication No. 98-N001.)

6 O'Connor AM, Fiset V, DeGrasse C, Graham ID, Evans W, Stacey D, et al. Decision aids for patients considering health care options: evidence of efficacy and policy implications. Monogr Natl Cancer Inst (in press).

7 O'Connor AM, Fiset V, Rostom A, Tetroe J, Entwistle V, LlewellynThomas H, et al. Decision aids for people facing health treatment or screening decisions (protocol for a Cochrane review). In: Cochrane Collaboration. Cochrane Library. Issue 1. Oxford: Update Software, 1999.

8 Charles C, Gafni A, Whelan T. Shared decision-making in the medical encounter: What does it mean? Soc Sci Med 1997;44:681-92

9 Entwistle VA, Sowden AJ, Watt IS. Evaluating interventions to promote patient involvement in decision making: by what criteria should effectiveness be judged? J Health Serv Res Policy 1998;3:100-7.

10 Llewellyn-Thomas H. Presidential address-patients' health care decision making: a framework for descriptive and experimental investigations. Med Decis Making 1995;15:101-6.

11 Mulley A. Outcomes research: Implications for policy and practice. In Smith R, Delamothe T, eds. Outcomes in clinical practice. London: BMJ Publishing, 1995:13-27.

12 O'Connor AM, Tugwell P, Wells GA, Elmslie T, Jolly E, Hollingworth G, et al. A decision aid for women considering hormone therapy after menopause: decision support framework and evaluation. Patient Educ Counsel. 1998;33:267-79.

13 Rothert M, Talarcyzk GJ. Patient compliance and the decision making process of clinicians and patients. J Compliance Health Care 1987:2:55-71.

14 Mulrow CD, Oxman A. How to conduct a Cochrane systematic review. Version 3.0.2. Oxford: Cochrane Collaboration, 1997.

15 Barry MJ, Cherkin DC, Chang YC, Fowler FJ, Skates S. A randomized trial of a multimedia shared decision-making program for men facing a treatment decision for benign prostatic hyperplasia. Disease Management and Clinical Outcomes 1997;1:5-14.

16 Bernstein SJ, Skarupski KA, Grayson CE, Starling MR, Bates ER, Eagle KA. A randomized controlled trial of information-giving to patients referred for coronary angiography: effects on outcomes of care. Health Expectations 1998;1:50-61.

17 Clancy CM, Cebul RD, Williams SV. Guiding individual decisions: a randomized, controlled trial of decision analysis. Am J Med 1988;84:283-8.

18 Davison BJ, Degner LF. Empowerment of men newly diagnosed with prostate cancer. Cancer Nursing 1997;20:187-96.

19 Davison BJ, Kirk P, Degner LF, Hassard TH. Information and patient participation in screening for prostate cancer. Patient Educ Counsel. 1999:37:255-63

20 Flood AB, Wennberg JE, Nease RFJ, Fowler FJJ, Ding J, Hynes LM. The importance of patient preference in the decision to screen for prostate cancer. Prostate Patient Outcomes Research Team. J Gen Inter Med 1996;11:342-9.

21 Herrera AJ, Cochran B, Herrera A, Wallace B. Parental information and circumcision in highly motivated couples with higher education. Pediatrics 1983;71:233-4.

22 Lerman C, Biesecker B, Benkendorf JL, Kerner J, Gomez-Caminero A, Hughes C, et al. Controlled trial of pretest education approaches to enhance informed decision-making for BRCA1 gene testing. J Nat Cancer Inst 1997;89:148-57.

23 Maisels JM, Hayes B, Conrad S, Chez RA. Circumcision: the effect of information on parental decision making. Pediatrics 1983;71:453-4.

24 Michie S, Smith D, McClennan A, Marteau TM. Patient decision making: an evaluation of two different methods of presenting information about a screening test. Br J Health Psychol 1997;2:317-26.

25 Morgan MW. A randomized trial of the ischemic heart disease shared decision making program: an evaluation of a decision aid [Master's thesis]. Toronto: University of Toronto, 1997

26 O'Connor AM, Tugwell P, Wells GA, Elmslie T, Jolly E, Hollingworth G, et al. Randomized trial of a portable, self-administered decision aid for postmenopausal women considering long-term preventive hormone therapy. Med Decis Making 1998;18:295-303.

27 Phillips C, Hill BJ, Cannac C. The influence of video imaging on patients' perceptions and expectations. Angle Orthodontist 1995;65:263-70.

28 Rothert ML, Holmes-Rovner M, Rovner D, Kroll J, Breer L, Talarczyk G, et al. An educational intervention as decision support for menopausal women. Res Nursing Health 1997;20:377-87.

29 Street RLJ, Voigt B, Geyer CJ, Manning T, Swanson GP. Increasing patient involvement in choosing treatment for early breast cancer. Cancer 1995; 76:2275-85.

30 Thornton JG, Hewison J, Lilford RJ, Vail A. A randomised trial of three methods of giving information about prenatal testing. BMJ 1995;311:1127-30.

31 Wolf AM, Nasser JF, Schorling JB. The impact of informed consent on patient interest in prostate-specific antigen screening. Arch Intern Med 1996;156:1333-6.

32 Gruppen LD, Margolin J, Wisdom K, Grum C. Outcome bias and cognitive dissonance in evaluating treatment decisions. Acad Med 1994;10(suppl):S57-9.

(Accepted 19 August 1999) 